\section{Interrupting Ebola}

\section{By Tracey Baas, Senior Editor}

The 2014 Ebola outbreak is the largest in the disease's history and the first in West Africa, where it has reached multiple countries. Although an approved therapy looks far away, five of seven patients given an experimental combination of $\mathrm{mAbs}$ are still alive. But that therapy is only one of several in development, and it is all hands on deck now to push the programs into the clinic.

The ZMapp antibody cocktail from Mapp Biopharmaceutical Inc. is a composite of different mAbs that Mapp, Defyrus Inc., the Public Health Agency of Canada and the University of Manitoba have been working on for at least two years.

The pipeline also contains vaccines and oligonucleotides against Ebola and its close relative, Marburg virus (see Table 1, "Filovirus pipeline"). Researchers polled by SciBX said that the different approaches should be pursued in parallel given the severity and urgency of the outbreak.

"There is a place for all of these different strategies, such as siRNAs, mAb cocktails and vaccines," said Erica Ollmann Saphire. "Different options might be used at different times."

Ollmann Saphire is a professor of immunology and microbial science at The Scripps Research Institute and director of the Viral Hemorrhagic Fever Immunotherapeutic Consortium.

She said that a vaccine, which would generally be used before exposure to the virus, could be given to aid workers, scientists and people living in or near an outbreak. Antibody and siRNA-based therapies would generally be used post-exposure, although pre-exposure antibodies or post-exposure high-dose vaccines might also work.

Now, each of the modalities has received support from three independent studies that showed specific antibodies, vaccines or siRNAs can prevent or treat disease in nonhuman primates. ${ }^{1-3}$

\section{ZMapp cocktail}

ZMapp is being developed as a therapeutic for infected individuals, and although it has been used in a small number of patients on a compassionate use basis, it still has safety hurdles to satisfy in controlled clinical trials.

The cocktail contains two components from the ZMAb antibody mix provided by a team from the Public Health Agency of Canada and University of Manitoba, and one MB-003 component provided by Mapp. The MB-003 mix contained three human or human-mouse chimeric mAbs, whereas ZMAb was a combination of three mouse mAbs targeting Ebola glycoproteins.

In previous work, the Canadian team showed that ZMAb was partially protective in nonhuman primates when given after fever and virus in the blood were detected. Likewise, earlier work by Mapp showed that MB-003 - combined with an interferon- $\alpha$ (IFNA; IFN- $\alpha$ )expressing adenovirus adjuvant-protected 7 out of 8 nonhuman primates when given up to 72 hours after infection.

Now, the Canadian and Mapp researchers have combined components of the two mixes to find a cocktail that has greater efficacy and can extend the treatment window compared with either MB-003 or ZMAb.

The group used a series of Ebola challenge experiments in guinea pigs and nonhuman primates and screened different mAb combinations to find which provides the best antiviral response. The screen yielded two triple-antibody cocktails, ZMapp1 and ZMapp2, that each contained one MB-003-derived and two ZMAb-derived mAbs.

Next, the researchers compared ZMapp1 and ZMapp2 in nonhuman primates in a study of the Ebola Kikwit variant in which the cocktail was given via i.v. administration three times at three-day intervals, three days after infection.

ZMapp1 produced a better outcome than ZMapp2, as it controlled viremia better, and led to survival of six of six rhesus macaques compared with five of six for ZMapp2 and zero of two for mock treatment.

Each of the three ZMapp1 antibodies target different epitopes on the Ebola glycoprotein, which suggested there is a low chance that escape mutants would be a significant problem. Escape mutants occur when replicating viruses accumulate mutations in antibody recognition sites, which reduces the antibodies' ability to neutralize the virus.

In a second Ebola challenge study, ZMapp1 protected 18 of 18 rhesus macaques when given via i.v. administration 3 times at 3 -day intervals, even when the cocktail was started 5 days after infection. In addition, the cocktail reversed disease symptoms such as elevated liver enzymes, mucosal hemorrhages and rash.

Although ZMapp1 was not directly tested against the Ebola Guinean strain responsible for the West African outbreak, sequence homology studies and in vitro binding assays suggested the mAbs would have comparable neutralizing activities to those shown against the Kikwit strain.

ZMapp1 is now called ZMapp.

"What we observed in the nonhuman primate studies was beyond all of our expectations," said Gary Kobinger. "The ZMapp-treated rhesus macaques all recovered and show no adverse effects at this time." Kobinger is chief of special pathogens for the Public Health Agency of Canada team, an associate professor of medical microbiology at the University of Manitoba and adjunct professor of pathology and laboratory medicine at the Perelman School of Medicine at the University of Pennsylvania.

He said that the next steps would be dose-ranging studies in rhesus macaques to determine the minimal dose required to prevent death in animals with different levels of viremia. "Another thing that needs to be determined is the point of no return," he added. "If substantial tissue and organ damage has already occurred, increasing the dose of ZMapp won't matter."

Results were published in Nature.

According to Ollmann Saphire, the study provides strong support 
Table 1. Filovirus pipeline. At least 16 products for filovirus are in development by public and private companies. Gray indicates therapies highlighted in the story.

Source: BCIQ: BioCentury Online Intelligence

\begin{tabular}{|c|c|c|c|c|}
\hline Strategy & Compound & Description & Team & Development \\
\hline \multirow{6}{*}{ Vaccines } & VSV-Ebola vaccine & $\begin{array}{l}\text { Recombinant vesicular stomatitis virus (VSV) vector } \\
\text { expressing Ebola antigens }\end{array}$ & $\begin{array}{l}\text { NewLink Genetics Corp. } \\
\text { (NASDAQ:NLNK); Public } \\
\text { Health Agency of Canada; NIH; } \\
\text { U.S. Department of Defense } \\
\text { (DOD) }\end{array}$ & IND cleared \\
\hline & $\begin{array}{l}\text { National Institute of } \\
\text { Allergy and Infectious } \\
\text { Diseases/GlaxoSmithKline } \\
\text { plc (LSE:GSK; NYSE:GSK) } \\
\text { Ebola vaccine (VRC- } \\
\text { EBOADC069-00-VP) }\end{array}$ & $\begin{array}{l}\text { Chimpanzee-derived adenoviral vectors expressing } \\
\text { Ebola or Marburg antigens }\end{array}$ & $\begin{array}{l}\text { GlaxoSmithKline; NIH; } \\
\text { Wellcome Trust; Medical } \\
\text { Research Council; } \\
\text { U.K. Department for } \\
\text { International Development }\end{array}$ & Phase I \\
\hline & Ebola/Marburg vaccine $e^{\mathrm{B}, \mathrm{C}}$ & $\begin{array}{l}\text { Multivalent vaccine using a recombinant adenovirus } \\
\text { platform expressing Ebola or Marburg antigens }\end{array}$ & $\begin{array}{l}\text { Johnson \& Johnson (NYSE:JNJ); } \\
\text { NIH }\end{array}$ & Phase I \\
\hline & Combination Ebola vaccine & $\begin{array}{l}\text { Prime-boost vaccine using two components derived } \\
\text { from AdVac technology from Crucell N.V. and } \\
\text { MVA-BN technology from Bavarian Nordic A/S } \\
\text { (CSE:BAVA) }\end{array}$ & Bavarian Nordic; J\&J; NIH & $\begin{array}{l}\text { Preclinical; will } \\
\text { start Phase I } 2015\end{array}$ \\
\hline & $\begin{array}{l}\text { SynCon Ebola and Marburg } \\
\text { DNA vaccine }\end{array}$ & $\begin{array}{l}\text { Synthetic DNA consensus Ebola and Marburg } \\
\text { vaccine }\end{array}$ & $\begin{array}{l}\text { Inovio Pharmaceuticals Inc. } \\
\text { (NASDAQ:INO); NIH; DOD }\end{array}$ & Preclinical \\
\hline & VesiculoVax & $\begin{array}{l}\text { Vesiculovirus vectors (such as VSV) expressing } \\
\text { Ebola or Marburg antigens }\end{array}$ & Profectus BioSciences Inc.; NIH & Preclinical \\
\hline \multirow[t]{2}{*}{ Antibodies } & ZMapp & $\begin{array}{l}\text { Cocktail of mAbs that target unique sites on the } \\
\text { Ebola virus envelope glycoproteins }\end{array}$ & $\begin{array}{l}\text { Defyrus Inc.; Mapp } \\
\text { Biopharmaceutical Inc.; } \\
\text { Biomedical Advanced Research } \\
\text { and Development Authority }\end{array}$ & $\begin{array}{l}\text { Preclinical; will } \\
\text { start Phase I } 2015\end{array}$ \\
\hline & TKM-Ebola (TKM-100201) & $\begin{array}{l}\text { Combination of siRNAs targeting Zaire } \\
\text { Ebola L polymerase, Zaire Ebola membrane- }\end{array}$ & Tekmira; DOD & $\begin{array}{l}\text { Phase I on } \\
\text { partial hold }\end{array}$ \\
\hline
\end{tabular}

associated protein (VP24) and Zaire Ebola polymerase complex protein (VP35) formulated with lipid nanoparticle technology from Tekmira Pharmaceuticals Corp. (TSX:TKM; NASDAQ:TKMR)

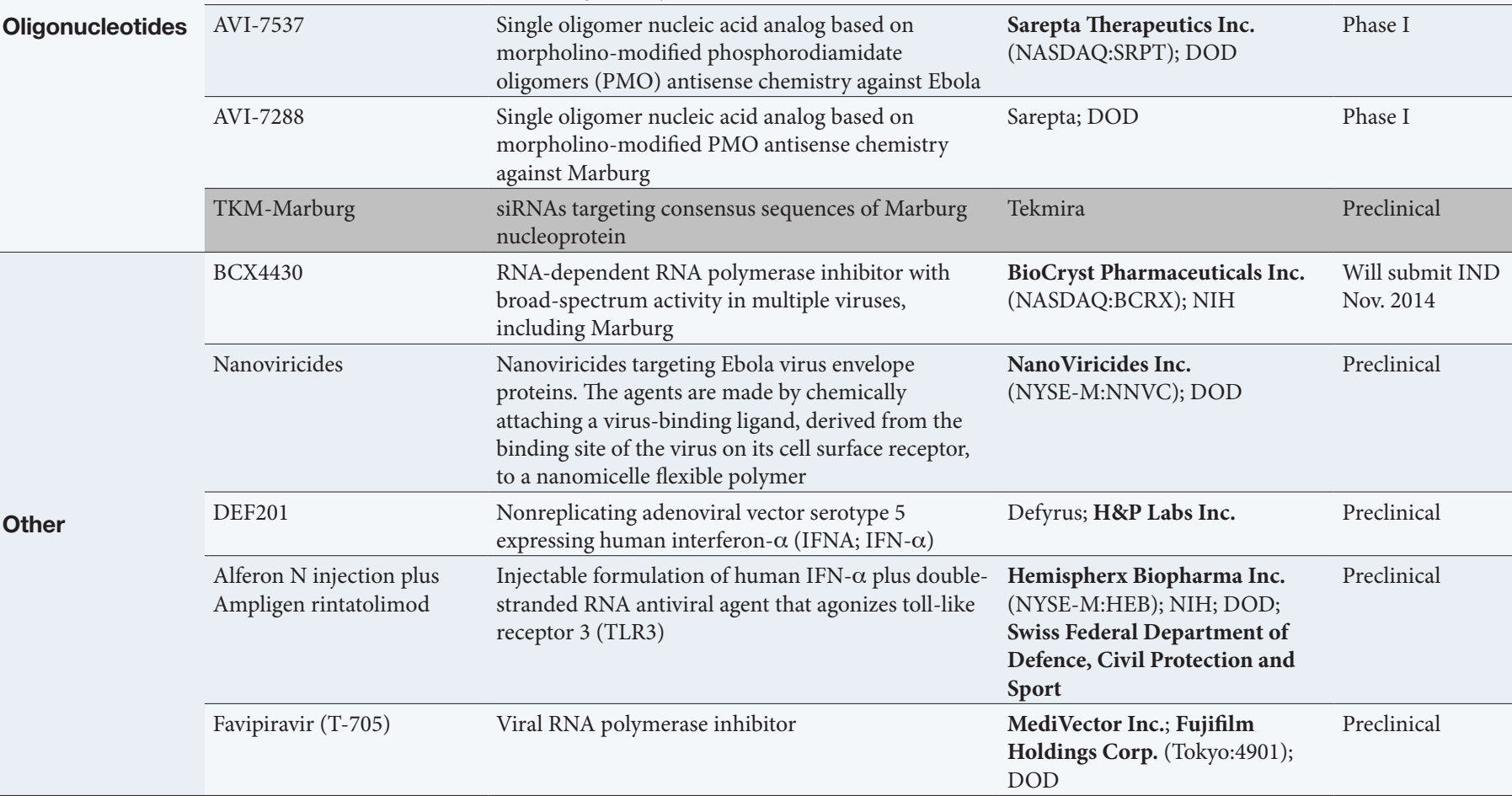

AFrom 2013 acquisition of Okairos AG. BFrom 2011 acquisition of Crucell N.V. ' Development of Ebola program suspended after termination of funding by DOD in 2012. 
for the antibody-based approach to Ebola. "The ability of the antibodies to reverse the course of the disease and confer $100 \%$ survival to laboratory animals late in infection suggests that antibody treatments are of practical use in real-world scenarios," she told SciBX.

"The reason I am investing so much time in the Viral Hemorrhagic Fever Immunotherapeutic Consortium is because of the extremely compelling data on how well antibodies can work, both early and late in infection," she added. The consortium is made up of several companies and about 20 academic laboratories across 7 nations.

Patrick Iversen, VP of research and innovation at Sarepta Therapeutics Inc., said that because the data suggest ZMapp would neutralize the Ebola Guinean variant, "it would be interesting to see if ZMapp would also be predicted to neutralize the viruses in the 99 people whose Ebola virus genomes were recently sequenced."

In September, Mapp received a $\$ 24.9$ million, 18 -month contract to develop and manufacture ZMapp from the U.S. Department of Health \& Human Services Office of the Assistant Secretary for Preparedness and Response (ASPR), and ASPR has the option to provide an additional $\$ 17.4$ million to take it through the regulatory process at the FDA. ASPR's Biomedical Advanced Research and Development Authority will provide Mapp with funds to produce enough ZMapp for preclinical studies and early human safety trials, with a goal of FDA approval.

In addition, $\$ 58$ million out of $\$ 88$ million approved by the U.S. House of Representatives for the Ebola epidemic has been earmarked to speed production of ZMapp and two vaccine candidates.

Patent and licensing status were undisclosed by Mapp. The Canadian government holds a patent on the mAbs $2 \mathrm{G} 4$ and $4 \mathrm{G} 7$, which are two of the antibodies included in the final ZMapp cocktail.

\section{Prime-boost for Ebola}

In parallel, a team from the NIH's National Institute of Allergy and Infectious Diseases (NIAID) Vaccine Research Center (VRC) showed that an anti-Ebola vaccine can provide protection in a nonhuman primate model of infection.

Although human adenovirus-based vaccines have previously shown protection against Ebola, their efficacy is limited because most people have pre-existing immunity to adenovirus caused by routine seasonal exposure to the virus.

The NIAID-led team thus turned to nonhuman sources of adenoviruses and prioritized chimpanzee-derived adenovirus (ChAd) vectors as they have been used in human trials against other pathogens. Previous studies at the VRC showed that ChAd vectors are not neutralized by human anti-adenovirus sera and protect mice from mouse-adapted Ebola virus infection. ${ }^{4}$

The ChAd-based vaccines were provided by Okairos AG. GlaxoSmithKline plc acquired the vaccine company in 2013.

In the new study, the NIAID team evaluated combinations of chimpanzee-derived replication-defective adenovirus 3 (ChAd3), ChAd63 and modified vaccinia Ankara (MVA) for their ability to protect nonhuman primates against an Ebola challenge.

In cynomolgus macaques immunized with vaccine vectors expressing Ebola glycoprotein, the ChAd3-based vector produced higher levels of anti-glycoprotein antibodies and antigen-specific $\mathrm{T}$ cells than the ChAd63-based vector. The ChAd3 vaccine also induced greater numbers of $\mathrm{CD}^{+} \mathrm{T}$ cells that simultaneously produced tumor necrosis factor (TNF) and IFN- $\gamma$ (IFNG), which are associated with immune effector responses.

In a follow-up study, 2 of 4 ChAd3-immunized rhesus macaques survived challenge with Ebola virus 10 months after immunization.

To increase protection against Ebola, the researchers wanted to incorporate a prime-boost strategy because double-shot immunization is known to elicit more potent immune responses than single-shot vaccinations. The team gave the ChAd3-glycoprotein vaccine to macaques and then gave a booster immunization with a second Ebola glycoproteinexpressing vector two months later.

The optimal double-shot combination was a ChAd3-MVA prime-boost, which led to survival of 4 of 4 rhesus macaques challenged with Ebola virus 10 months after the first shot. By contrast, only one of three animals survived a ChAd3-ChAd3 prime-boost, and only one of four animals survived a ChAd3-ChAd63 combination.

In blood obtained from the macaques three months after the initial priming vaccination and before the Ebola challenge, ChAd3-MVA primeboosted rhesus macaques showed the highest levels of glycoproteinspecific antibody, $\mathrm{CD} 4^{+} \mathrm{T}$ cell responses and $\mathrm{CD} 8^{+}$memory $\mathrm{T}$ cells that simultaneously produce TNF, IFN- $\gamma$ and IL-2, which are associated with immunological memory.

Results were published in Nature Medicine.

According to spokesperson Mary Anne Rhyne, director of U.S. external communications for GSK, the data suggest the ChAd vectors could provide a significant advantage over earlier vaccine attempts. "The results of preclinical studies and clinical studies indicate that this chimpanzee adenovector technology may be capable of stimulating an antigen-specific $\mathrm{CD}^{+} \mathrm{T}$ cell response that holds the potential to address disease where classical vaccine technologies have not been successful," she said.

Rhyne added, "Conventional vaccines usually induce strong antibody and $\mathrm{CD}^{+} \mathrm{T}$ cell responses, but they often fail to induce a potent antigenspecific $\mathrm{CD}^{+} \mathrm{T}$ cell response. There is growing evidence that antigenspecific $\mathrm{CD}^{+} \mathrm{T}$ cells play a major role in the protection or treatment of a number of infectious diseases and cancer."

Iversen told SciBX that although the results are promising, he wanted to see surviving nonhuman primates from the study rechallenged with Ebola virus. "Rechallenge is cumbersome but absolutely necessary in order to prove that antibodies induced by the vaccine do not enhance disease upon rechallenge"

The NIH began Phase 1 trials of the vaccine in the U.S. on Sept. 2, and The Jenner Institute at the University of Oxford began a trial in the U.K. last week. GSK will being manufacturing about 10,000 additional doses of the candidate vaccine and will work with the World Health Organization to determine how available vaccine doses could be used for an emergency immunization program for healthcare workers and other high-risk groups.

The Wellcome Trust, the Medical Research Council and the U.K. Department for International Development provided a $£ 2.8$ million (\$4.7 million) grant to fund trials of an Ebola vaccine candidate from GSK and the NIAID.

Patent and licensing status were undisclosed by the NIAID.

In addition, another Ebola vaccine candidate based on a vesicular stomatitis virus vector is being developed by NewLink Genetics Corp.'s BioProtection Systems Corp. subsidiary. The company was awarded $\$ 1$ million by the U.S. Department of Defense's Defense Threat Reduction 
Agency to perform IND-enabling preclinical toxicity studies, and IND status for the vaccine has been cleared.

\section{Ebola making antisense}

Whereas antibodies and vaccines are traditional antiviral tools, no examples of siRNAs have yet been marketed to treat or prevent viral infections.

However, in the third study, a joint team from The University of Texas Medical Branch at Galveston and Tekmira Pharmaceuticals Corp. created an siRNA against the Ebola-related Marburg filovirus (MARV) and showed that it can provide antiviral protection in guinea pigs and primates.

The siRNA, dubbed NP-718m, is targeted at the MARV nucleoprotein in a region that contains only one nucleotide mismatch between the Ravn and the Angola or Ci67 strains. Of the three, the Angola strain is associated with the highest mortality in naturally occurring human outbreaks-being responsible for about $90 \%$ mortality in over 200 confirmed cases-and shows a faster disease course in nonhuman primates than the other two strains.

In February, the team published data showing that lipid nanoparticle delivery of anti-MARV nucleoprotein siRNA one hour after infection protected guinea pigs in a lethal outbreak model of infection. The study showed $100 \%$ post-exposure protection against the Angola and Ci67 strains and 60\% protection against the Ravn strain. ${ }^{5}$

Now, the team has tested whether NP-718m could have therapeutic potential against MARVAngola when given at longer times post-exposure in nonhuman primates.

The researchers gave lipid nanoparticleencapsulated NP-718m to 21 rhesus macaques challenged with MARV-Angola at different times post-infection.

NP-718m protected all animals given siRNA 30-45 minutes, 24 hours, 48 hours or 72 hours after infection. Four animals were included in each treatment group. None of the animals survived that received control siRNA or no compound. Seventy-two hours is considered the earliest time point at which viral RNA can be detected for diagnosis.

The siRNA-based therapeutic also decreased levels of virus in blood and tissues and decreased signs of clinical illness such as lesions, coagulopathy, liver dysfunction, fever and skin rash compared with no treatment or lipid nanoparticle-control siRNA.

NP-718m is now called TKM-Marburg.

Results were published in Science Translational Medicine.

Thomas Geisbert, lead author on the study, told SciBX that the team's next steps are to extend the studies in nonhuman primates for treatment times measured in days rather than hours. "Wed really like to see where the point of no return is for using LNP-NP-718m as a post-exposure therapeutic," he said.

Geisbert is a professor of microbiology and immunology at the University of Texas Medical Branch.

A related siRNA-based compound (TKM-Ebola) from Tekmira was previously tested in Phase I studies but was placed on partial clinical hold by the FDA owing to flu-like symptoms in some subjects. This week, Tekmira received authorization from the FDA to provide TKM-Ebola for treatment under expanded access protocols to subjects with confirmed or suspected Ebola. Geisbert was also the lead researcher in studies of TKMEbola in nonhuman primates in 2010.

According to Geisbert, siRNA-based therapeutics are simpler and faster to prepare than antibody-based therapeutics or some vaccines. "One benefit of using an siRNA-based therapeutic is that producing a filovirus-specific siRNA therapeutic is relatively fast compared to producing filovirus-specific antibodies or some vaccines," he said. "Sequence surveillance really can direct the sequence used to produce lipid nanoparticle-encapsulated siRNAs."

He added that whereas Marburg virus tends to have high sequence homology between different strains, Ebola species vary significantly. However, siRNA provides flexibility that enables multiple strains or possibly species to be targeted. "There's no reason why a cocktail of different Ebola virus siRNAs couldn't be formulated with the lipid nanoparticles," he said.

Iversen thought it would be important to characterize how the siRNA affected cytokine response.

"Because initial Phase I studies suggested the product could be producing an inflammatory response, follow-up Phase I studies will have to monitor cytokine profiles very carefully to be certain the therapy is not interfering with the innate immune response. siRNAs are known to induce the innate immune response through toll-like receptors," he said.

Geisbert responded that the Tekmira team is testing the safety of TKM-Ebola in a multi-ascending dose Phase I trial in healthy individuals.

This week, an Ebola virus-infected American physician received TKM-Ebola under compassionate use. He also received a blood transfusion from an American doctor who had contracted Ebola and survived. The blood transfusion could provide passive transfer of neutralizing antibodies against the virus.

The University of Texas Medical Branch, Profectus BioSciences Inc., Tekmira and the Vanderbilt University Medical Center have been awarded up to $\$ 26$ million to advance treatments-including siRNA, antibodies and vaccines - for Ebola and Marburg viruses.

Patent and licensing status of the lipid nanoparticle compound containing NP-718m (TKM-Marburg) were undisclosed by Tekmira. The company has not disclosed its next steps.

\section{Breaking into Ebola}

Although the crisis has sparked momentum in anti-Ebola therapies and the compounds might be made available for compassionate use, they still need to go through controlled clinical trials before they can receive regulatory approval.

Indeed, Anthony Fauci, director of the NIAID, told BioCentury This Week that public health strategies are likely to have a greater effect on this outbreak than are compounds in the pipeline.

"It's unrealistic to think that all of a sudden vaccines are going to turn around and stop this outbreak. It's going to be the infection control and the typical public health measures that are going to do it," he said. 
What will have the most impact in controlling "the epidemic is a massive infusion of resources in the form of hospital beds, the ability to isolate, the ability to contact trace, the ability to care for people with the proper personal protective equipment that healthcare workers have," Fauci said.

According to Ollmann Saphire, controlled clinical trials could be valuable for understanding the disease despite their complexities. "Typically, what is needed to advance any treatment is a double-blind, placebo-controlled trial," she said. "Usually, outbreaks are smaller and are contained more rapidly, so a trial isn't appropriate or feasible. In contrast, this outbreak is growing in scale. A trial actually could be done and would garner the human efficacy data. That kind of data is more useful than data from animal models alone."

She noted that controlled trials are complicated in diseases such as Ebola as they necessarily involve a placebo group.

"The decision to include a placebo control in these studies could be morally difficult because it means that some Ebola patients would receive a placebo in place of the experimental treatment. However, they do receive the current standard of care, and a double-blind, placebo controlled trial is the only way to prove efficacy. We owe it to the people in the next outbreak to have that data."

"Anyway, the current outbreak involves thousands of people. In these early stages, there may be many more people than doses of experimental drug or vaccines available. Regardless, if enrolled in a trial, people would at least receive the current standard of care such as fluids and pain relief, and that medical care improves the odds of survival by itself," she said.

Baas, T. SciBX 7(37); doi:10.1038/scibx.2014.1088

Published online Sept. 25, 2014

\section{REFERENCES}

1. Thi, E.P. et al. Sci. Transl. Med.; published online Aug. 20, 2014; doi:10.1126/scitranslmed.3009706

Contact: Thomas W. Geisbert, The University of Texas Medical Branch at Galveston, Galveston, Texas e-mail: twgeisbe@utmb.edu

Contact: Ian MacLachlan, Tekmira Pharmaceuticals Corp., Burnaby, British Columbia, Canada e-mail: imaclachlan@tekmirapharm.com
2. Qiu, X. et al. Nature; published online Aug. 29, 2014; doi:10.1038/nature13777

Contact: Gary P. Kobinger, Public Health Agency of Canada, Winnipeg, Manitoba, Canada

e-mail: gary.kobinger@phac-aspc.gc.ca

Contact: Larry Zeitlin, Mapp Biopharmaceutical Inc., San Diego, Calif. e-mail: larry.zeitlin@mappbio.com

3. Stanley, D.A. et al. Nat. Med.; published online Sept. 7, 2014; doi:10.1038/nm.3702

Contact: Nancy J. Sullivan, National Institutes of Health, Bethesda, Md. e-mail: njsull@mail.nih.gov

4. Quinn, K.M. et al. J. Immunol. 190, 2720-2735 (2013)

5. Ursic-Bedoya, R. et al. J. Infect. Dis. 209, 562-570 (2014)

\section{COMPANIES AND INSTITUTIONS MENTIONED}

Biomedical Advanced Research and Development Authority, Washington, D.C.

Defense Threat Reduction Agency, Washington, D.C.

Defyrus Inc., Toronto, Ontario, Canada

Food and Drug Administration, Silver Spring, Md.

GlaxoSmithKline plc (LSE:GSK; NYSE:GSK), London, U.K.

The Jenner Institute, Oxford, U.K.

Mapp Biopharmaceutical Inc., San Diego, Calif.

Medical Research Council, London, U.K.

National Institute of Allergy and Infectious Diseases,

Bethesda, Md.

National Institutes of Health, Bethesda, Md.

NewLink Genetics Corp. (NASDAQ: NLNK), Ames, lowa

Perelman School of Medicine at the University of Pennsylvania,

Philadelphia, Pa.

Profectus BioSciences Inc., Baltimore, Md.

Public Health Agency of Canada, Winnipeg, Manitoba, Canada Sarepta Therapeutics Inc. (NASDAQ:SRPT), Cambridge, Mass.

The Scripps Research Institute, La Jolla, Calif.

Tekmira Pharmaceuticals Corp. (TSX:TKM; NASDAQ:TKMR), Burnaby, British Columbia, Canada

University of Manitoba, Winnipeg, Manitoba, Canada

University of Oxford, Oxford, U.K.

The University of Texas Medical Branch at Galveston,

Galveston, Texas

U.K. Department for International Development, London, U.K.

U.S. Department of Defense, Washington, D.C.

U.S. Department of Health \& Human Services, Washington, D.C. Vanderbilt University Medical Center, Nashville, Tenn.

Wellcome Trust, London, U.K.

World Health Organization, Geneva, Switzerland 